\title{
A TRIPLE-WIN SCENARIO FOR HORIZONTAL COLLABORATION IN LOGISTICS: DETERMINING ENAB LING AND KEY SUCCESS FACTORS
}

\author{
Antonio Palmie ri* \\ School of Economics and Management \\ Università Carlo Cattaneo - LIUC \\ C.so Matteotti 22 \\ 21053 Castellanza (VA), Italy \\ tel. +39.0331 .572111$ \\ e-mail: apalmieri@ liuc.it
}

\section{Frances co Pomponi}

REBEL - Resource Efficient Built Environment Lab

Edinburgh Napier University, UK

email: F.Pomponi@napier.ac.uk

\section{Angeloantonio Russo}

Department of Management

LUM University

S.S. $100 \mathrm{~km} 18$

70010 Casamassima (BA), Italy

tel. +39.080 .6978111$

fax. +39.080 .6977122$

email: russo@lum.it

* Corresponding author 


\title{
A TRIPLE-WIN SCENARIO FOR HORIZONTAL COLLABORATION IN LOGISTICS: DETERMINING ENABLING AND KEY SUCCESS FACTORS
}

\begin{abstract}
Horizontal collaborations emerged as a new strategic option in the logistics sector during the last decade. However, successful implementation of horizontal collaborations is far from a developed issue due to several barriers that exist or emerge when setting up such collaborative projects. This study aims at identifying the enabling factors supporting successful implementation of horizontal collaborations in the logistics sector, and in identifying key success factors that logistics service providers (LSPs) should consider. Results from a withinand cross-case analysis of two horizontal collaboration projects in the contract logistics sector support the proposed theoretical framework, highlighting both enabling and key success factors of horizontal collaborations. The former refers to factors that are related to LSPs, customers, and industries, while the latter results in a triple-win scenario characterised by LSP competences, trust, and environmental management orientation of successful horizontal collaboration projects.
\end{abstract}

Keywords: horizontal collaboration; logistics; logistic service provider

\section{INTRODUCTION}

Firms often consider logistics as a cost that is unlikely to contribute to competitive advantage. Moreover, logistics activities require technological and capital expenditure, which compels firms to outsource these complex activities. In recent years, increasing attention has been devoted to the environmental impact that logistics activities generate (Lan and Zhong, 2018).

Within this context, logistics service providers (LSPs) are considered a preferred partner capable of offering logistics services to overcome the above-mentioned problems. It is seen that LSPs invest in resources and competences to offer logistics services that are assumed efficient, innovative, and eco-friendly. In recent years, both scholars and practitioners suggested new forms of collaboration in logistics as a critical factor that determines the success and competitiveness of companies (Naesens et al., 2009). Horizontal collaboration is an unexplored strategic option that related literature is focusing on under a theoretical perspective, despite the growing number of publications in the past few years (Pomponi et al., 2015).

Horizontal collaborations can provide many benefits to customers: a single-delivery charge versus a larger delivery reduces the number of trips, less packaging for products, less product wastage, and overall better visibility. They also have the benefit of reducing fuel costs and increasing the utilization of vehicles, thereby lowering carbon emissions.

Nevertheless, open questions still exist about how horizontal collaborations are managed. In other words, the relevant literature still lacks a thorough and comprehensive investigation of the key factors that address the success or failure of horizontal collaborations in the logistics sector. Thus, first, we focus on the role of specific enabling factors that can boost the successful implementation of horizontal collaborations; subsequently, we discuss the relations that exist between the enabling and key success factors of these peculiar projects. 
The results are based on both within- and cross-case analysis of two horizontal collaboration projects developed by Ceva Logistics Italia during 2008-2015. The findings of these case studies are translated into a theoretical framework for presenting both enabling and key success factors of horizontal collaborations. Note that enabling factors are related to LSP, customers, and industry. On the other hand, key success factors show a triple-win scenario characterised by LSP competences, trust, and environmental management orientation of successful horizontal collaboration projects.

This study contributes to theory and practice and shows that successful implementation of horizontal collaboration depends on (1) competences of LSPs, which require higher levels of experience and innovativeness for more efficient implementation of operations related to logistics services; (2) trust between partners involved in the project, as they share part of the logistics activities with other companies (typically, competitors); and (3) overall environmental management orientation of the project, which depends on the implementation of horizontal collaboration, that is, competences of LSPs; on the other hand, it is a key factor for the success of the project.

The remainder of the article is organised as follows. In Section 2, relevant literature on horizontal collaborations in logistics is reviewed. Section 3 presents the research design. Section 4 presents the findings of the study, while Section 5 discusses the findings. Finally, Section 6 highlights the main research contributions as well as limitations and presents opportunities for future study.

\section{LITERATURE REVIEW}

\section{Theoretical foundations of horizontal collaborations}

Management scholars have studied collaboration in logistics over decades (e.g., Caputo and Mininno, 1996), and there is broad agreement that it is a critical factor for the success and competitiveness of companies (inter alia Naesens et al., 2009). Among the possible forms of cooperation in logistics, horizontal collaboration is perhaps the latest entry into the family and, therefore, the related literature is becoming mature despite the growing number of publications (Pomponi et al., 2015).

Horizontal collaboration is defined by the European Commission (2001) as a concerted practice between companies operating at the same level(s) in the value system, which is consistent with the seminal literature on the subject. For collaborations to succeed, it is necessary to start from Lambert et al. (1999, p.166), who defined collaboration in logistics as 'a tailored business relationship based on mutual trust, openness, shared risk, and shared reward that yields a competitive advantage resulting in business performance greater than would be achieved by the firms individually'. Therefore, horizontal collaboration aims to identify and achieve winwin situations among two or more firms operating at the same level of the supply chain, whether or not they are competitors regardless of their size. The rationale is that such collaboration allows the companies involved to obtain a superior performance than they would achieve individually.

Pomponi et al. (2015) identified a key role for the success of horizontal collaborations in something that characterises nearly all human interactions: trust. Trust between partners, as well as each of the assets that have to be shared when cooperating, represents a critical factor for the success of collaboration, although this aspect was never investigated empirically and has so far remained only at the theoretical level (Pomponi et al., 2015). 
Relying on a deep review of the literature in supply chain management, Pomponi et al. (2015) suggest that strong theoretical foundations to investigate horizontal collaborations in logistics have to be based on a theoretical pluralism. In this regard, several organizational theories explain the relationships between companies in the supply chain. In line with the transaction cost economics theory, some authors highlight that adequate governance mechanisms must be implemented to cope with conflicts among partners and to prevent opportunism (Schmoltzi and Wallenburg, 2012). On the other hand, social exchange theory has also been applied to logistics, horizontal collaborations in particular, to show the limitations of transaction cost economics theory and foresee behaviours and interactions in collaborations (Halldorsson et al., 2007). Additionally, resource dependence theory helps to comprehend how and to what extent industry structure influences horizontal collaborations and where the bargaining power can be used. Resource dependence theory, therefore, explains the relationship between environmental uncertainty and strategic supply chain management (Paulraj and Chen, 2007). Although the above theories are used in the literature to establish an evolutionary perspective on collaborations, additional contribution is provided by the social dilemma theory. The latter predicts why a partner would adopt a collaborative and long-term oriented approach, while others would pursue a non-collaborative and short-term oriented approach. Therefore, social dilemma theory explains partners' behaviour and their level of commitment in horizontal collaborations (McCarter and Northcraft, 2007).

Relying on such theoretical pluralism, we further investigate trust among partners as well as additional factors that can influence horizontal collaborations in logistics literature. In fact, trust was considered a critical success factor by Daudi et al. (2016), who focussed on - in their review-behavioural factors influencing trust. Their systematic review revealed four common factors that have either a positive or negative influence on the success of logistics collaboration, namely (1) information sharing, (2) incentive alignment, (3) decision synchronization, and (4) opportunism (Daudi et al., 2016). The authors further divided these four factors into thirteen criteria, all of which aim to be measurable quantities to assess the success of collaboration.

Similarly, Sanchez Rodrigues etal. (2015) scrutinize the various factors influencing the success of cooperation. Their study examined not just the issues between the partners but also all the other actors involved. As a result, they identified several factors that support the development of success in horizontal collaborations such as legislation, common suppliers and delivery bases, and capable 3PLs (third-party logistics) in addition to trust amongst the various partners (Sanchez Rodrigues et al., 2015). These findings seem to indicate that governments, the wider supply chain, and 3PLs and LSPs all have a fundamental role to play in the success of horizontal collaboration.

The key role of 3PLs and LSPs and the potential for these figures to rise to a more determinant and full-bodied role of orchestrator of the collaboration has already been identified by Rossi (2012) within the EU 7FP funded project $\mathrm{CO}^{3}$, which specifically examined collaboration concepts for co-modality. Such a figure was named 'trustee' within the $\mathrm{CO}^{3}$ project precisely for the fundamental role it played (Rossi, 2012).

A broader look at the critical success factors can be found in Pfoser et al. (2016) who, through a review of the literature and expert interviews, classified such factors under three main macrocategories related to transport, customers, and external conditions. Notably, they also found an important role for policy and governments in the factors influenced by external conditions and showed that a behavioural shift is perhaps the most important factor related to customers.

As far as behavioural issues are concerned, Wallenburg and Raue (2011) found conflict to be one of the main reasons for the failure of collaborative endeavours. This aspect has been studied in more recent research where Wallenburg and Schäffler (2016) found that adopting 
collaborative practices in the performance measurement of horizontal collaborations between LSPs significantly reduces the overall level of conflict.

Kumar et al. (2016) surveyed Indian small and medium-sized enterprises to understand the key elements to success when cooperating in a specific context. They observed that selection and evaluation of appropriate suppliers, inclusion of customers in the decision-making process, and greater use of information and communication technologies have a significant impact on the performance of the surveyed businesses.

Lan and Zhong (2018) investigated what is necessary to facilitate sustainability in logistics, which represents the second rationale to embark on a collaborative partnership, the first being monetary savings. They found that the key factors are represented by the development of infrastructure and the logistics industry, as well as technological development available within the relevant supply chains.

Companies in the transport and logistics industry have a significant impact on the environment (Oberhofer and Dieplinger, 2014). Environmental sustainability is a key issue for these firms, such that LSPs recognise environmental sustainability as a strategic priority, even though they approach the issue in different ways (Evangelista et al., 2017). Environmental sustainability is not only a concept that influences the re-design and re-conceptualization of supply chains (Ansari and Kant, 2017a, b) but it also guides the articulation of business strategy. In effect, competitive advantage can be obtained by developing sustainable products or services to satisfy customers' needs (Carballo-Penela et al., 2017; Seuring and Müller, 2008), and such logic also applies to logistics services such as horizontal collaboration projects.

\section{Research questions}

All these studies, which represent the most recent and comprehensive contributions to a field of research that is yet to reach full maturity, have the following elements in common. They identify a key actor for the success of cooperation in the LSP; and/or they are based on reviews of the relevant literature, surveys, or expert interviews; and/or they investigate collaborations in the logistics sector providing directions on the comprehension of the success of such strategic options, which are critical and dependent variables that remains unexplored yet. In other words, the existing literature still lacks a thorough and comprehensive investigation of the key factors that can address the success or failure of horizontal collaborations in logistics.

Relying on the above literature, this study represents a first attempt to fill this gap in the literature through a qualitative investigation of existing best practices in the logistics sector. Therefore, detailed research questions are proposed and investigated, as follows:

Do enabling factors exist that firms should consider addressing for the successful implementation of horizontal collaborations in the logistic s sector?

What are the main characteristics of the enabling factors that affect the results of horizontal collaborations?

How do these enabling factors influence keysuccess factors, which boost the successful implementation of horizontal collaborations?

\section{RESEARCH DESIGN}

\section{Methodology}

This study relies on the assumption that the case study methodology is suitable to answer the 'how' and 'why' research questions (Y in, 2009). This is one of the most powerful research 
methods for theory building (Eisenhardt, 1989). The multiple-case study technique is typically suggested because it overcomes some of the limitations of a single-case study approach (e.g., generalizability of conclusions), and the results are more compelling and robust (Herriott and Firestone, 1983). Multiple cases also enable replication logic, which is central to building theory (Eisenhardt, 1989). Given that a multiple case technique does not necessarily mean multiple-firm identification, Voss et al. (2002) highlighted that study of a single firm may involve a number of different cases.

Translating the case study methodology in the above reviewed literature into logistics, some important considerations emerge supporting the study's research design. First, there are no case studies focused on how LSPs orchestrate horizontal collaboration and manage relationships between various customers. Second, this research is designed to focus on a multiple case study approach involving two different cases in the logistics sector. Therefore, selection of case studies, as described below, involved a sample which is theoretically and empirically consistent with the recommendations made by Eisenhardt (1989) and Meredith (1998). In particular, analysis was conducted using several steps. We first performed a within-case analysis to become familiar with each case and allow the unique pattern of each case to emerge. Next, we performed cross-case analysis to search for cross-case patterns. In order to facilitate comparison between cases, we used cross-case synthesis. We created word tables showing the data from individual cases according to an ad hoc framework (Yin, 2009).

\section{Case selection}

The case selection process started with an analysis of the logistics market in Europe with detailed focus on the contract logistics sector, valued at 383 billion euros (41\% of the complete European logistics market) in 2012 (Schwemmer, 2013). Next, we focused on the largest market players active in the contract logistics sector; in particular, we excluded firms pursuing their activity exclusively in the postal sector, which is not considered part of the logistics sector. We identified the twenty biggest LSPs based on the revenue generated in Europe, as reported by the European Commission (2015); in other words, both multinational and national LSPs were under review. These LSPs were competing for market leadership and there was a concrete possibility of finding data and information on horizontal collaborations developed by these players. Therefore, newspapers and social media as well as public reports for each LSP were analysed for content to identify horizontal collaboration projects launched by these players.

This process allowed us to identify the case of Ceva Logistics Italia (hereafter, Ceva), which is the Italian subsidiary of Ceva Logistics, a leading global LSP. The company operates through subsidiaries in more than 160 countries, employs over 40,000 people, and offers contract logistics and freight management services.

Ceva is the Italian subsidiary characterised by a functional organizational structure managed by a director who reports to the headquarters. Ceva is active in the Italian market, reaching a value of more than 40 billion euros in the contract logistics sector in 2015 (European Commission, 2015). The Italian subsidiary accounts for more than $7 \%$ of the total Group revenue and employs about 1,800 employees, representing an important pillar of the Group.

Ceva significantly fits with the aim of this study for several reasons. First, the company is recognised as an innovator in the field of horizontal collaboration services. Second, there was a good relationship between the researchers and the company. This enabled vital access to data and information and guaranteed a productive and collaborative spirit in the research.

Ceva started offering horizontal collaboration services in 2010, which represents a significant innovation in the market (Figure 1). For Ceva, horizontal collaboration means pooling of resources between various customers. These customers are manufacturers who sell similar 
products and compete in the same market. Ceva acts as an LSP, offering a common hub to customers where there is pooling of human resources, processes, equipment, transportation vehicles, information technologies, and best practices.

[Figure 1 near here]

Based on the experience of Ceva, this study addresses two different units of analysis within the company, that is, two different projects of horizontal collaboration were selected. The first project, launched in 2010, is 'the City of Books', and the second, launched in 2015, is the 'Tyre City'. The City of Book is dedicated to the publishing industry while the Tyre City addresses manufacturers of tyres. The two selected studies are cases in which the company implemented horizontal collaboration using two different industries. The cases provide insights into the horizontal collaboration process. Table 1 summarises the characteristics of the sample.

[Table 1 near here]

\section{Data collection}

Data and information were collected from several sources and through various methods, including semi-structured interviews, documentation, and archival records. The use of multiple sources is fundamental to perform data triangulation, namely collecting information from multiple sources aimed at corroborating the same facts (Yin, 2009).

Following Yin (2009), we decided to use documents to corroborate and increase evidence from other sources, such as interviews. The company provided several documents and archival records describing its strategic decisions and actions with respect to horizontal collaboration.

The semi-structured interviews were carried out both within the company and outside. Totally, eight Ceva managers were interviewed as well as other managers responsible for logistics and/or supply chain matters among the customers of City of Books and Tyre City. Overall, twenty interviews were conducted. The selection of Ceva managers was made to have key informants for the two projects of horizontal collaboration. These managers occupied various positions in the organization working at different functional levels, such as key account management, business development, operations, and engineering. In particular, the key account and business development managers were selected because of their proximity to customers. The operations managers are familiar with operations within the hubs. Finally, most of the engineering managers had in depth knowledge of the solutions (technologies, equipment, and human resources) adopted in each hub (see Appendix I for a complete list of the interviewees).

Overall, the research design was developed following the main criteria for qualitative research suggested in the literature (Voss et al., 2002; Yin, 2009). First, we triangulated the data and had key informants review the draft case study reports to check for the construct validity of our research design. That is, using multiple sources was fundamental to perform data triangulation, namely the collection of information from multiple sources aimed at corroborating the same facts. Second, external validity was controlled applying a replication technique in the design of multiple case studies to verify the generalizability of the results. In other words, the same set of questions, protocols, and case study reports were used during data collection and analysis of the different cases under investigation. Third, the criterion-related internal validity was fulfilled through identifying the causal relationships between certain conditions and the use of the pattern-matching logic. Last, we ascertained the reliability of our research design and results by using an ad hoc protocol for data collection. During each interview, six main themes and additional six sub-topics (i.e., one for eachmain theme) were identified and discussed. The themes and sub-topics referred to the main characteristics of horizontal collaborations and the related issues, respectively. Throughout each interview, the interviewer guided the conversations to ensure that all the questions contained in the protocol were addressed, and 
each theme and sub-topic was covered with one or more open questions, which were the starting point for an open talk with the interviewee (structure of the interview protocol is reported in Appendix II). The managers reviewed the interview transcripts to check and confirm the contents. Once confirmed, they provided inputs during the process of writing the draft case study reports. As a final check, having interviews with managers responsible for different activities allowed us to improve the reliability of our results, reaching diverse perspectives on a single issue.

\section{FINDINGS}

The main findings are presented below. First, the results of the within-case analysis are presented; subsequently, results from the cross-case analysis for both the projects are investigated in the study.

Within-case findings: The City of Books

The City of Books opened in 2010 with two customers. In fact, Ceva Logistics Italia was able to convince the two customers, previously managed by traditional outsourcing service contracts, to converge into a single hub to secure various advantages for the company and customers. Therefore, we identified a first set of enabling factors of the project related to relationships with customers. During an interview, the key account manager for the project said:

'We had the idea for a new service of horizontal collaboration, and then we asked our two customers whether they were interested in this new project. The project required that each customer would accept the other. We needed to have at least two customers to start the project and to justify the new investment and reduce risks of the market. It was clear that the first customers of City of Books would have to be our old customers because we had strong relationships with them that were built on trust'.

A second enabling factor of the project was linked to the competitive system within the industry. In particular, competition in the publishing industry was not based on outbound logistics. As a logistics manager actively involved in the project with one of the customers of City of Book said:

'In our industry, competition is based on specific elements of the products, such as the book's title and author(s). Therefore, we can partner with our competitors on outbound logistics'.

Another enabling factor was customers' cost structure. In fact, the publishing companies' logistics costs constituted a significant part of total costs. Thus, publishing companies were attracted by the possibility of reducing logistics costs to increase efficiency and ensure higher business profitability.

Moreover, another point could be considered an advantage for starting this innovative project. In fact, publishing companies used the same physical selling points (i.e., bookshops and largescale retailers) to distribute their products. Indisputably, Ceva, therefore, had an advantage in terms of efficiency, offering a common hub to customers where there was pooling of human resources, equipment, and transportation vehicles. Therefore, Ceva could possibility offer a new service at a lower price than traditional outsourcing, thereby increasing its attractiveness as an LSP in the market.

There were specific conditions to develop the City of Books project. However, there were different phases in the project, which took four years from the identification of the project until 
market penetration results were attained (see Figure 2 for a detailed analysis of the timing of the project).

\section{[Figure 2 near here]}

In 2008, there was only a single innovative idea and it was necessary to make an in depth study of the project analysis. The starting point was the benchmarking activity, which was of critical relevance to analyse and identify the most developed logistics systems in terms of technologies, infrastructure, and organizational processes. The next phase was designing the optimal solution. This activity was complex because it was necessary to find the right balance between the degree of automation, flexibility of the system, and the overall cost of the project. In fact, as a project manager said during an interview:

'A high degree of automation reduced the flexibility of the solution and simultaneously increased the cost of the project. We had to find the right solution to guarantee the project's economic sustainability'.

The optimal solution was building a logistics hub in a strategic position for the Italian logistic s flows and characterised by more than 100,000 pallet seats, a modern information technology (IT) system capable of controlling and managing the inbound and outbound flows, and the employment of 200 human resources.

After finding the right solution, customers with whom Ceva already had a contract had to be contacted to show them the advantages of switching to this new solution. This phase was central to understanding customers' ideas about the project and their willingness to take part in it.

In the last months of 2008, the top management of Ceva knew that the project already had two customers and conditions were ideal to develop detailed business plans and payback period analysis. The results of an economic and financial analysis convinced shareholders to invest. The City of Books was built during 2009 and it opened in 2010 in Stradella, near the city of Pavia. The logistics site covered an area of $47,000 \mathrm{~m}^{2}$ in 2010 , and as stated, it opened with only two customers. By 2011, market penetration was underway and was characterised by a huge commercial effort to acquire new customers. At end of 2016, City of Books covered an area of $80,000 \mathrm{~m}^{2}$ and served six customers.

\section{Within-case findings: Tyre City project}

The success of the City of Books project pushed Ceva to look for new business opportunities. At that point, the chief executive officer (CEO) believed in horizontal collaboration services and wanted to offer it to other industries to expand market share. The shareholders approved his vision. The CEO and the top management team worked together to identify other industries that could be penetrated by scaling both experience and empirical evidence gained from the City of Books project and Ceva's customer portfolio.

In 2014, the final decision was to focus on tyre manufacturers due to the presence of specific conditions to launch the project. First, the company had developed expertise in the logistics of tyre manufacturers, with some of them as customers managed by traditional outsourcing services. This assumption implies that Ceva exploited its previous experience as the first enabling factor of the project, in terms of both experience in offering logistics services in the tyre manufacturing industry as well as managing innovative services.

Second, competitive factors in the tyre manufacturing industry did not include outbound logistics. In fact, one supply chain manager working with a customer of Tyre City said: 
'Competition in our industry is based on different factors. The main factors are innovation, quality of the products, and brand equity'.

This implies that sharing of routines and processes related to logistics activities would not have been a constraint for tyre manufacturers. This result highlights that if firms perceive logistics activities as low value-adding factors, they are more willing to share these processes with competitors by joining the same horizontal collaboration project.

Third, the logistics costs of tyre manufacturers amounted to a large percentage of their total costs. Therefore, the Tyre City project would have had a positive impact on these companies, reducing their logistics costs and improving their profitability. Finally, tyre manufacturers used the same tyre fitting service companies and large-scale retailers to sell their products. This physical distribution channel structure constituted an advantage point for Ceva to optimise its distribution and transportation phase. Thus, Ceva could achieve a higher degree of efficiency, reducing its costs and thereby offering a competitive price to its customers.

The Tyre City project started in 2014 and is characterised by various phases that are presented in Figure 2, compared to the City of Book project. The first phase was benchmarking. The previous City of Book project supported Ceva's management team to facilitate this analysis, as they were acquainted with the most advanced logistics systems and had to evaluate techniques that were suitable to handle and store tyres. The second phase was about designing an optimal solution. There was a great debate about selecting a location for the logistics hub. The hub was strategically located in Somaglia, in the province of Lodi. Ceva decided to execute a logistics platform dedicated to warehousing, handling, and cross docking of products in the tyre sector.

The subsequent phase included presentation of the project to customers who already had a contract with Ceva to demonstrate the advantages of switching to this new solution. Two customers showed significant interest in this project and declared their willingness to switch to the new solution. Therefore, the condition to undertake the next step of the project, that is, elaboration of a detailed business plan and payback period analysis, convinced Ceva's shareholders to invest in the new project.

Tyre City was inaugurated in 2015-almost one year after the project had started. To fill the available space, market penetration commenced in 2015. The logistics site covered an area of more than $80,000 \mathrm{~m}^{2}$, indicating that new customers had to be enlisted as quickly as possible. By the end of 2016, Tyre City had six customers.

\section{Cross-Case Findings: City of Books and Tyre City projects}

Comparison of the two projects features the similarities and differences on the conditions that had agreed to implementing the plan in terms of the activities that were realised.

First, Ceva conceived City of Books - its first horizontal collaboration project-when its brand was recognised in the market as an LSP and it already had a few publishing companies as its own customers, who were managed by traditional outsourcing services. Similarly, the idea of a second horizontal collaboration project was generated some years after the first project was launched, when the brand was also associated with this innovative service and the company had a few tyre manufacturers in its customer portfolio.

A second common element is linked to the competitive environment that characterised the publishing and tyre manufacturing industries. Detailed competitive factors emerged during the case analysis, but did not include outbound logistics. In other words, companies engaged in both the publishing of books and manufacturing of tyres did not consider outbound logistics as a driver to achieve a competitive advantage. Therefore, the companies used logistics 
outsourcing and launched new solutions to achieve a higher degree of efficiency in logistics, even though these solutions were based on sharing resources and collaborating with competitors.

A third condition that is present in both projects is customers' cost structure. In fact, logistic s costs constituted a significant part of the total costs for publishing companies. Similarly, logistics costs amounted to a large percentage of total costs for tyre manufacturers. Thus, the publishing and tyre manufacturing companies were attracted to the possibility of reducing logistics costs to increase efficiency and ensure higher business profitability. Thus, horizontal collaboration projects addressed these business goals.

Finally, there is another common point between the two projects. Customers presented the same structure in terms of physical distribution channels in both the sectors, that is, publishing of books and manufacturing of tyres. Bookshops and large retailers characterised the former; the latter used large-scale retailers and tyre fitting service companies to sell their products. In both projects, Ceva was able to optimise its distribution and transportation services, offering a common logistics hub to customers, which involved pooling of human resources, technologies, and transportation vehicles. Thus, Ceva achieved a higher degree of efficiency, and was willing to offer a lower price for this new service than traditional outsourcing.

Most of the activities carried out during the implementation of projects presented the same sequence characterised by seven different phases, ranging from benchmarking to market penetration. The second project, Tyre City, was characterised by higher speed of execution. In fact, it was one year, from 2014 to 2015, to move from benchmarking to launching the service in the market. Instead, it took more than two years (2008-2010) to realise the same activities in the City of Books project and ended up with a three-year life cycle, from 2008 to 2011, to reach market penetration. Therefore, we argue that previous experience in project management was critical for Ceva in order to reduce the time to market for horizontal collaboration projects.

\section{DISCUSSION}

\section{Exploring the enabling factors of horizontal collaborations}

Horizontal collaboration is a big challenge in logistics because it requires inter-firm collaboration and integration, which can be difficult to achieve for a variety of reasons. The aim of this study is to identify potential enabling factors and their characteristics, which determine the key success factors of horizontal collaborations in the logistics sector. Previous research has addressed the critical role LSPs play for successful horizontal collaboration (Sanchez Rodrigues et al., 2015). The Ceva case study confirms the significant role of LSPs. This company succeeded in launching innovative horizontal collaboration services in logistics and also facilitated the adoption of this practice among its customers. Empirical evidence from the Tyre City and City of Books projects suggests that there are specific enabling factors of horizontal collaborations. As a result, both practitioners and academics consider this practice complex, even though its positive impact on firm performance is recognised. Therefore, the enabling factors identified through our analysis are discussed; subsequently, the theoretical and managerial implications associated with the relationship between the enabling and key success factors of horizontal collaborations are shown in the form of a general theoretical framework of this study.

First, horizontal collaboration services are activated by LSPs with a long and successful history in the traditional outsourcing market. In this sense, collaborative logistics seems to be an advancement of the traditional outsourcing service. Therefore, LSPs willing to offer successful horizontal collaboration services should rely on resources and competences that provide the 
LSP with innovative capacity. In other words, horizontal collaborations require a certain rate of innovation to be attractive to customers and for success. Moreover, LSPs with previous experience in the logistics sector are willing to manage innovative horizontal collaboration services that are attractive to customers. If Ceva customers involved in the first two horizontal collaborations did not belong to traditional outsourcing business areas, Tyre City and City of Books would have not been launched.

Another enabling factor is competition intensity within the industry. Horizontal collaborations take place if logistics services are not perceived as a competitive factor; that is, customers are interested in participating in horizontal collaboration in logistics and are open to associating with their competitors. In such cases, competition is mediated through horizontal collaborations managed by the LSP. Otherwise, if customers compete on logistics, it is likely that they will be interested in maintaining their own individuality without sharing resources with their competitors. There are various competitive factors within the tyre manufacturing and publishing industry, but they are not related to logistics.

Finally, two enabling factors can be grouped into the customer-related macro-category defined by Pfoser et al. (2016): customer cost structure, and structure of the physical distribution channel. With regard to customer cost structure, empirical evidence of Tyre City and City of Books shows that customers are more likely to be involved in horizontal collaborations if logistics costs represent a larger percentage of the total costs. Customers want to reduce logistics costs to achieve higher business profitability through horizontal collaboration. Considering the physical distribution channel of customers, it is fundamental that customers have the same points of selling, so that LSPs can optimise their distribution and transportation phase (e.g., better management of the transportation fleet, economies of scale for warehousing, etc.). Thus, sector-focused multi-customer hubs and various selling points characterise the downstream part of the supply chain. These selling points represent the destination of the flow of goods coming from the hub. At each point, multi-customer cargoes arrive and make it possible for the LSP to optimise various processes.

Connecting enabling and key success factors in horizontal collaborations: a theoretical framework

The theoretical framework of this study is presented in Figure 3. While contributing to the debate on horizontal collaboration in logistics activated by LSPs, our theoretical framework distinguishes between enabling factors to start horizontal collaboration and critical factors for the successful implementation of this practice. Moreover, we also depict the possible relationships between enabling factors and key success factors.

[Figure 3 near here]

Horizontal collaboration is implemented if all the enabling factors described above are in place. The implementation phase includes various activities that LSPs have to undertake in a proactive manner. Empirical evidence from the Ceva case demonstrates that the first project of horizontal collaboration implemented by the LSP extends over a longer period than the other project. In fact, until its market launch, City of Books was extended over two years, while Tyre City was developed over a single year. This is attributable to the learning effect, which influences the bundle of competences developed by the LSP. To generalise this evidence, we argue thatafter the first learning phase-LSPs can accelerate the implementation of horizontal collaboration projects in logistics, thereby reducing the time to market due to improved ability to manage the start-up of such complex projects. Therefore, the first key success factor for horizontal collaboration is the set of competences and knowledge held by the LSP. Then, the higher the level of innovativeness and experience characterizing LSPs, the higher will be the 
level of competences LSPs exploit for the successful implementation of horizontal collaborations.

There is another significant point for the successful implementation of horizontal collaboration projects in logistics. Without the presence of customers with whom Ceva had already developed business relations for traditional outsourcing services, it would not have been possible to develop either of the two projects. Therefore, we provide evidence that a critical factor for the success of horizontal collaborations is trust between the LSP and every customer involved in horizontal collaboration, as theoretically suggested in previous research (Pomponi et al., 2015). In particular, the degree of trust required is high and depends on previous business relations. If previous business relations are positive and the degree of trust between the partners is high, then LSPs can maximise the probability of implementing a successful project. Therefore, we argue that trust within horizontal collaborations (i.e., between LSPs and customers, as well as among customers) is directly influenced by the enabling factors identified in this study. Namely, more experienced and innovative LSPs inspire confidence and trust among the partners of a project; second, if LSPs offer efficient logistic services and share a physical distribution channel among customers, they are more willing to create a positive environment in which partners experience trust. Lastly, competition-based factors negatively affect the successful implementation of horizontal collaborations. This implies that if partners recognise that logistics services are not competitive factors in the market, they are willing to share their experience and resources with others. As a result, this creates mutual trust in a project.

A key success factor of horizontal collaborations that has emerged through this analysis is the environmental management orientation of the project. The results of our study demonstrate that choosing a horizontal collaboration strategy proves beneficial for the environment across the entire life cycle of transportation activities. Primary data collected during interviews with Ceva staff revealed a reduction that was achieved in terms of reduced transportation distances as well as the number of trucks on the road. Following our theoretical framework, we argue that environmental management orientation represents a key success factor for a project that is directly influenced by the enabling factors of horizontal collaboration. Specifically, LSPs recognise the natural environment as a critical stakeholder in horizontal collaborations. Second, experience and innovation accelerate the level of implementation of eco-efficient services, thereby revealing the strategic relevance of environmental management orientation of a project to meet the requirements LSPs have potentially avoided. Lastly, environmental management orientation is a recent concept, which is theoretically affecting the competitiveness of a firm. Therefore, we argue that customers involved in horizontal collaborations should consider the environmental orientation of the project as a key factor that contributes to increase their efficiency and reputation.

Given the relevance of environmental issues associated with horizontal collaborations, we run additional analysis at two levels: single- and multiple-impact categories. First, we investigated the impact of climate change through a single metric, the Global Warming Potential (GWP), computed in $\mathrm{CO} 2$ equivalent $(\mathrm{kgCO} 2 \mathrm{e})$ over a period of 100 years. In more detail, we followe d the impact assessment method developed by the IPCC (Intergovernmental Panel on Climate Change) (Stocker et al., 2013). Therefore, two scenarios are considered: the first refers to GWP emissions for horizontal collaboration; the second refers to the non-collaborative scenario, which is considered as the base case. Comparing the two scenarios based on the data provided in the IPCC (Stocker et al., 2013), the case of horizontal collaboration shows a GWP impact of $70.21 \mathrm{kgCO} 2 \mathrm{e}$ compared to $87.77 \mathrm{kgCO} 2 \mathrm{e}$ of the base case. The results imply a net reduction of approximately $17.5 \mathrm{kgCO} 2 \mathrm{e}$ if horizontal collaborations are implemented, that is, $25 \%$ reduction compared to the non-collaborative scenario. 
Since single-metric assessments can sometimes be misleading as they cannot capture issues of the so-called burden shifting (Hellweg and Milà i Canals, 2014), that is when a beneficial effect in one impact category causes detrimental increases across other categories, a second analysis was carried out. In more detail, to investigate the environmental consequences of horizontal collaboration across multiple impact categories, we relied on the ReCiPe Midpoint impact assessment method (Goedkoop et al., 2009). This method produces results across a broad range of environmental indicators and the midpoint version provides physical units for impact categories (the alternative endpoint indicator instead focuses on damages such as loss of species or human lives).

Table 2 presents the results of the analysis based on the multiple impact category base described above. Notwithstanding the impact category under consideration, the results confirm the lower impact of horizontal collaborations compared to the non-collaborative case. Specifically, horizontal collaborations confirm an environmental impact $25 \%$ lower than in the noncollaborative scenario, regardless of the impact category under investigation. Therefore, our results demonstrate that choosing a horizontal collaboration strategy proves beneficial for the environment across the entire life cycle of transportation activities, not just in terms of $\mathrm{CO} 2$ emissions but also across a broad range of environmental categories and indicators.

[Table 2 near here]

This analysis was conducted in SimaPro Release 8.5.2.0, which is based on the database EcoInvent 3 (Wernet et al., 2016). Transportation has been estimated through a Euro 3 lorry. Fuel consumption and emissions for the base case are for average European journeys and load factors. It is worth noting that the transport datasets used for the analysis refer to the entire life cycle of the transportation phase, that is, construction, operation, maintenance, and end-of-life stages and activities of vehicles and road infrastructure.

\section{CONCLUSIONS}

Horizontal collaboration, defined as collaboration between companies at the same level of the supply chain, has emerged in the last decade or so as a solution to problems in business logistics. Thus, LSPs can act as trustees and allow cooperation between companies that are often competitors. If successfully implemented, horizontal collaboration results in (1) higher efficiency for the LSP due to fewer journeys with higher loading factors, (2) lower costs for companies that share part of the logistics activities with other companies or competitors, and (3) reduced environmental impact.

Successful horizontal collaborations are difficult to achieve and, to the best of our knowledge, an insightful case study on real-world application of horizontal collaboration in logistics is missing. This study provides both theoretical and managerial implications to the debate in the field of logistics with an in-depth analysis of two different case studies. The two projects occurred in two different periods, and by assessing both, we could capture the elements of learning experienced by the LSP. Uniquely, by combining a within- with a cross-case analysis, we could identify the key enabling factors for the implementation of a horizontal collaboration project as well as the critical factors required for successful implementation of a horizontal collaboration initiative. Our empirical findings confirm the key role of trust between companies (i.e., LSPs' customers) and the LSP for a successful outcome of the collaboration, which were previously proposed only at the theoretical level. Moreover, we shed new light on the importance of LSP's competences to implement successful projects, as well as environmental management orientation, which represent a competitive factor that LSPs should carefully consider for implementing horizontal collaborations. 
Further theory building could follow up on the present study to understand to what extent the findings of this study and the proposed framework hold true in different contexts. Additionally, business managers can clearly identify the factors that enable horizontal collaboration and promote a trustworthy collaborative environment as the most important ingredient for success. With evidence from two successful implementations in practice, implications that are guidelines for future horizontal collaborations emerge from this study, thereby paving the road to reducing the risk of failure for collaborative projects.

\section{Limits and directions for future research}

The study limitations can be directions for future research. First, the number of cases analysed can reduce the generalizability of our results. Although we run a large number of interviews, additional efforts are required to investigate the large number of case studies, with additional emphasis on different sectors compared to what has been taken up in this study. Second, investigating additional cases can improve the scalability of the results offered in this study. Although qualitative research is a reliable methodology, future research can be developed with the aim of empirically testing the variables that emerged from this study. Detailed attention to study the operationalization and quantitative analysis of the enabling factors identified in this study (i.e., customer cost structure, customer physical distribution channel structure, LPSs' innovation and experience, and competitive factors) is necessary. Moreover, the potential relationship between the enabling and key success factors of horizontal collaborations $c$ an be empirically tested. Third, this study refers to a single country case. Although Ceva Logistics Italia is part of a multinational enterprise, the two projects investigated could experience the cultural effects that directly relate to the national perspective perceived during the interviews. Future studies should focus on controlling the country and cultural effects to improve the significance of the results or ensure that such effects are not a problem.

\section{REFERENCES}

Ansari, Z.N., Kant, R., 2017a. Exploring the framework development status for sustainability in supply chain management: a systematic literature synthesis and future research directions. Business Strategy and the Environment 26, 873-892.

Ansari, Z.N., Kant, R., 2017b. A state-of-art literature review reflecting 15 years of focus on sustainable supply chain management. Journal of Cleaner Production 142, 2524-2543.

Caputo, M., Mininno, V., 1996. Internal, vertical and horizontal logistics integration in Italian grocery distribution. International Journal of Physical Distribution \& Logistics Management 26, 64-90.

Carballo-Penela, A., Mateo-Mantecón, I., Alvarez, S., Castromán-Diz, J.L., 2017. The Role of Green Collaborative Strategies in Improving Environmental Sustainability in Supply Chains: Insights from a Case Study. Business Strategy and the Environment.

Daudi, M., Hauge, J.B., Thoben, K.-D., 2016. Behavioral factors influencing partner trust in logistics collaboration: a review. Logistics Research 9, 19.

Eisenhardt, K.M., 1989. Agency theory: An assessment and review. Academy of management Review 14, 57-74.

European Commission, 2001. Guidelines on the Applicability of Article 81 of the EC Treaty to Horizontal Cooperation Agreements. European Commission Notice 2001/C 3/02. European Commission, Brussels, Belgium. 
European Commission, 2015. Fact-finding studies in support of the development of an EU strategy for freight transport logistics. Lot 1: Analysis of the EU logistics sector. Final report. European Commission, Brussels, Belgium.

Evangelista, P., Colicchia, C., Creazza, A., 2017. Is environmental sustainability a strategic priority for logistics service providers? Journal of Environmental Management 198, 353362.

Goedkoop, M., Heijungs, R., Huijbregts, M., De Schryver, A., Struijs, J., Van Zelm, R., 2009. ReCiPe 2008. A life cycle impact assessment method which comprises harmonised category indicators at the midpoint and the endpoint level. ReCiPe.

Halldorsson, A., Kotzab, H., Mikkola, J.H., Skjøtt-Larsen, T., 2007. Complementary theories to supply chain management. Supply Chain Management: An International Journal 12, 284-296.

Hellweg, S., Milà i Canals, L., 2014. Emerging approaches, challenges and opportunities in life cycle assessment. Science 344, 1109-1113.

Herriott, R.E., Firestone, W.A., 1983. Multisite qualitative policy research: Optimizing description and generalizability. Educational researcher 12, 14-19.

Kumar, R., Singh, R.K., Shankar, R., 2016. Study on collaboration and information sharing practices for SCM in Indian SMEs. International Journal of Business Information Systems $22,455-475$.

Lambert, D.M., Emmelhainz, M.A., Gardner, J.T., 1999. Building successful logistics partnerships. Journal of Business Logistics 20, 165-182.

Lan, S., Zhong, R.Y., 2018. Coordinated development between metropolitan economy and logistics for sustainability. Resources, Conservation and Recycling 128, 345-354.

McCarter, M.W., Northcraft, G.B., 2007. Happy together?: Insights and implications of viewing managed supply chains as a social dilemma. Journal of Operations Management 25, 498-511.

Meredith, J., 1998. Building operations management theory through case and field research. Journal of Operations Management 16, 441-454.

Naesens, K., Gelders, L., Pintelon, L., 2009. A swift response framework for measuring the strategic fit for a horizontal collaborative initiative. International Journal of Production Economics 121, 550-561.

Oberhofer, P., Dieplinger, M., 2014. Sustainability in the transport and logistics sector: lacking environmental measures. Business Strategy and the Environment 23, 236-253.

Paulraj, A., Chen, I.J., 2007. Environmental uncertainty and strategic supply management: a resource dependence perspective and performance implications. Journal of Supply Chain Management 43, 29-42.

Pfoser, S., Treiblmaier, H., Schauer, O., 2016. Critical success factors of synchromodality: Results from a case study and literature review. Transportation Research Procedia 14, 1463-1471.

Pomponi, F., Fratocchi, L., Rossi Tafuri, S., 2015. Trust development and horizontal collaboration in logistics: a theory based evolutionary framework. Supply Chain Management: An International Journal 20, 83-97. 
Rossi, S., 2012. Challenges for co-modality in a collaborative environment, CO3 project, 7th framework program.

Sanchez Rodrigues, V., Harris, I., Mason, R., 2015. Horizontal logistics collaboration for enhanced supply chain performance: an international retail perspective. Supply Chain Management: An International Journal 20, 631-647.

Schmoltzi, C., Wallenburg, C.M., 2012. Operational governance in horizontal cooperations of logistics service providers: performance effects and the moderating role of cooperation complexity. Journal of Supply Chain Management 48, 53-74.

Schwemmer, M., 2013. Top 100 in European Transport and Logistics Services 2013/2014. Fraunhofer SCS, Nuremberg.

Seuring, S., Müller, M., 2008. Core issues in sustainable supply chain management-a Delphi study. Business Strategy and the Environment 17, 455-466.

Stocker, T.F., Qin, D., Plattner, G.-K., Tignor, M., Allen, S.K., Boschung, J., Nauels, A., Xia, Y., Bex, V., Midgley, P.M., 2013. Climate change 2013: The physical science basis, Intergovernmental Panel on Climate Change, Working Group I Contribution to the IPCC Fifth Assessment Report (AR5), Cambridge Univ Press, New York.

Voss, C., Tsikriktsis, N., Frohlich, M., 2002. Case research in operations management. International Journal of Operations \& Production Management 22, 195-219.

Wallenburg, C.M., Raue, J.S., 2011. Conflict and its governance in horizontal cooperations of logistics service providers. International Journal of Physical Distribution \& Logistics Management 41, 385-400.

Wallenburg, C.M., Schäffler, T., 2016. Performance measurement in horizontal LSP cooperation as a field of conflict: the preventive role of collaborative processes. Logistics Research 9, 7.

Yin, R.K., 2009. Case study research: Design and methods, 4th ed. Sage publications, Thousands Oak, CA. 
Table 1 - The features of the sample

\begin{tabular}{|c|ccccc|}
\hline Project & Location & $\begin{array}{c}\text { Launching } \\
\text { year }\end{array}$ & $\begin{array}{c}\text { Extension (m2 of } \\
\text { total surface) }\end{array}$ & $\begin{array}{c}\text { No. of customers inv olved in the project } \\
\text { Launching year }\end{array}$ & 2016 \\
\hline City of & Nearby the city of & 2010 & 80,000 & 2 \\
Books & Pavia & & 2 & 6 \\
Tyre City & Nearby the city of Lodi & 2015 & More than 80,000 & 2 \\
\hline
\end{tabular}


Table 2 - ReCiPe analysis: horizontal collaboration vs. non-collaborative scenario

\begin{tabular}{|c|c|c|c|c|}
\hline Impact category & Unit & $\begin{array}{c}\text { Non-collaborative scenario } \\
\text { (a) }\end{array}$ & $\begin{array}{l}\text { Horizontal collaboration } \\
\text { (b) }\end{array}$ & $\begin{array}{l}\text { Spread } \\
(a-b)\end{array}$ \\
\hline Stratospheric ozone depletion & kg CFC11 eq & 0.000031 & 0.000025 & 0.000006 \\
\hline Ionizing radiation & $\mathrm{kBq}$ Co-60 eq & 2.913 & 2.330 & 0.583 \\
\hline Ozone formation, Human health & kg NOx eq & 0.637 & 0.510 & 0.127 \\
\hline Fine particulate matter formation & $\mathrm{kg} P M 2,5$ eq & 0.148 & 0.119 & 0.030 \\
\hline Ozone formation, terrestrial ecosystems & kg NOx eq & 0.649 & 0.519 & 0.130 \\
\hline Terrestrial acidification & $\mathrm{kg} \mathrm{SO} 2 \mathrm{eq}$ & 0.342 & 0.273 & 0.068 \\
\hline Freshwater eutrophication & $\mathrm{kg} P$ eq & 0.00554 & 0.00443 & 0.00111 \\
\hline Marine eutrophication & $\mathrm{kg} \mathrm{N}$ eq & 0.00050 & 0.00040 & 0.00010 \\
\hline Terrestrial ecotoxicity & kg 1,4-DCB & $1,625.316$ & $1,300.252$ & 325.063 \\
\hline Freshwater ecotoxicity & kg 1,4-DCB & 1.217 & 0.974 & 0.243 \\
\hline Marine ecotoxicity & $\operatorname{kg} 1,4-\mathrm{DCB}$ & 2.393 & 1.915 & 0.479 \\
\hline Human carcinogenic toxicity & kg 1,4-DCB & 1.635 & 1.308 & 0.327 \\
\hline Human non-carcinogenic toxicity & kg 1,4-DCB & 46.969 & 37.575 & 9.394 \\
\hline Land use & m2a crop eq & 6.910 & 5.528 & 1.382 \\
\hline Mineral resource scarcity & $\mathrm{kg} \mathrm{Cu}$ eq & 0.138 & 0.110 & 0.028 \\
\hline Fossil resource scarcity & $\mathrm{kg}$ oil eq & 31.943 & 25.555 & 6.389 \\
\hline Water consumption & m3 & 0.304 & 0.243 & 0.061 \\
\hline
\end{tabular}


Figure 1 - How the horizontal collaboration service works

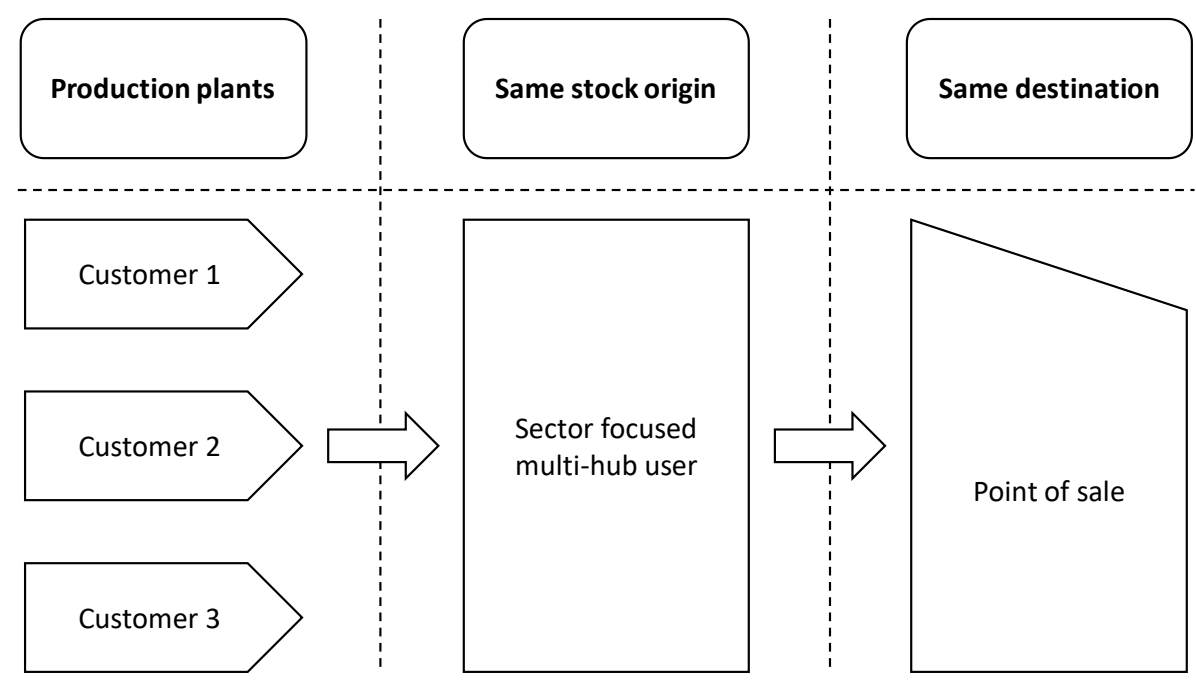

Source: Adaptation from Ceva Log is tics Italia internal reports 
Figure 2 - The sequential steps of the projects: City of Books vs. Tyre City

Tyre City project


Figure 3 - Theoretical framework: Enabling and key success factors in horizontal collaborations

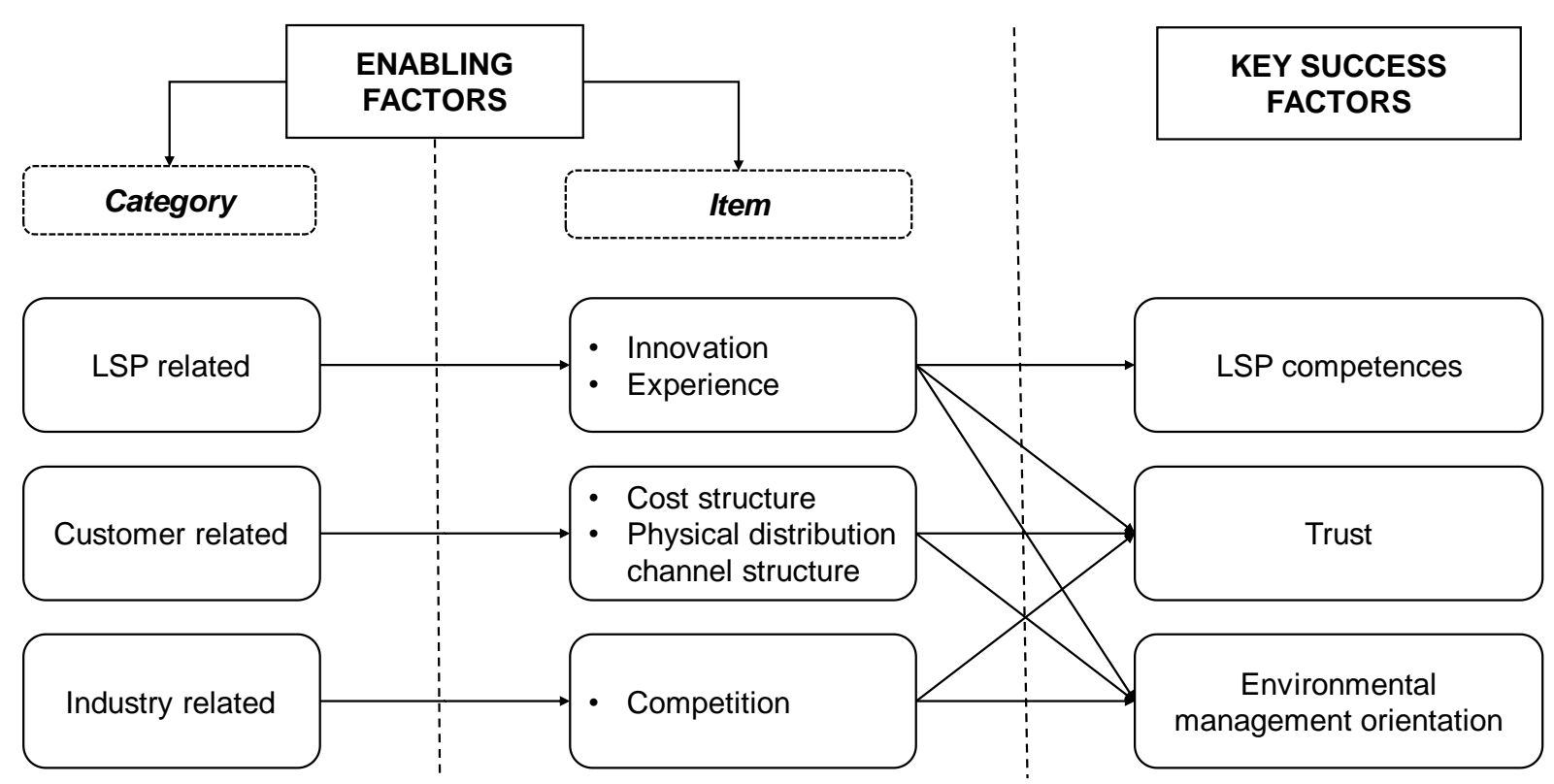




\section{APPENDIX I. List of intervie wees}

a) Interview participants in Ceva Logistics Italia

1. Vice President Business Development

2. Business Development Director

3. Key Account Manager - Publishing Industry

4. Key Account Manager - Tyre Industry

5. Operating Manager - Hub 'City of Books'

6. Operating Manager - Hub 'Tyre City'

7. Engineering Manager

8. Sales Manager

b) Interview participants in customers of Ceva Logistics Italia

12 Logistics and/or Supply Chain Managers 


\section{APPENDIX II. Structure of the interview protocol}

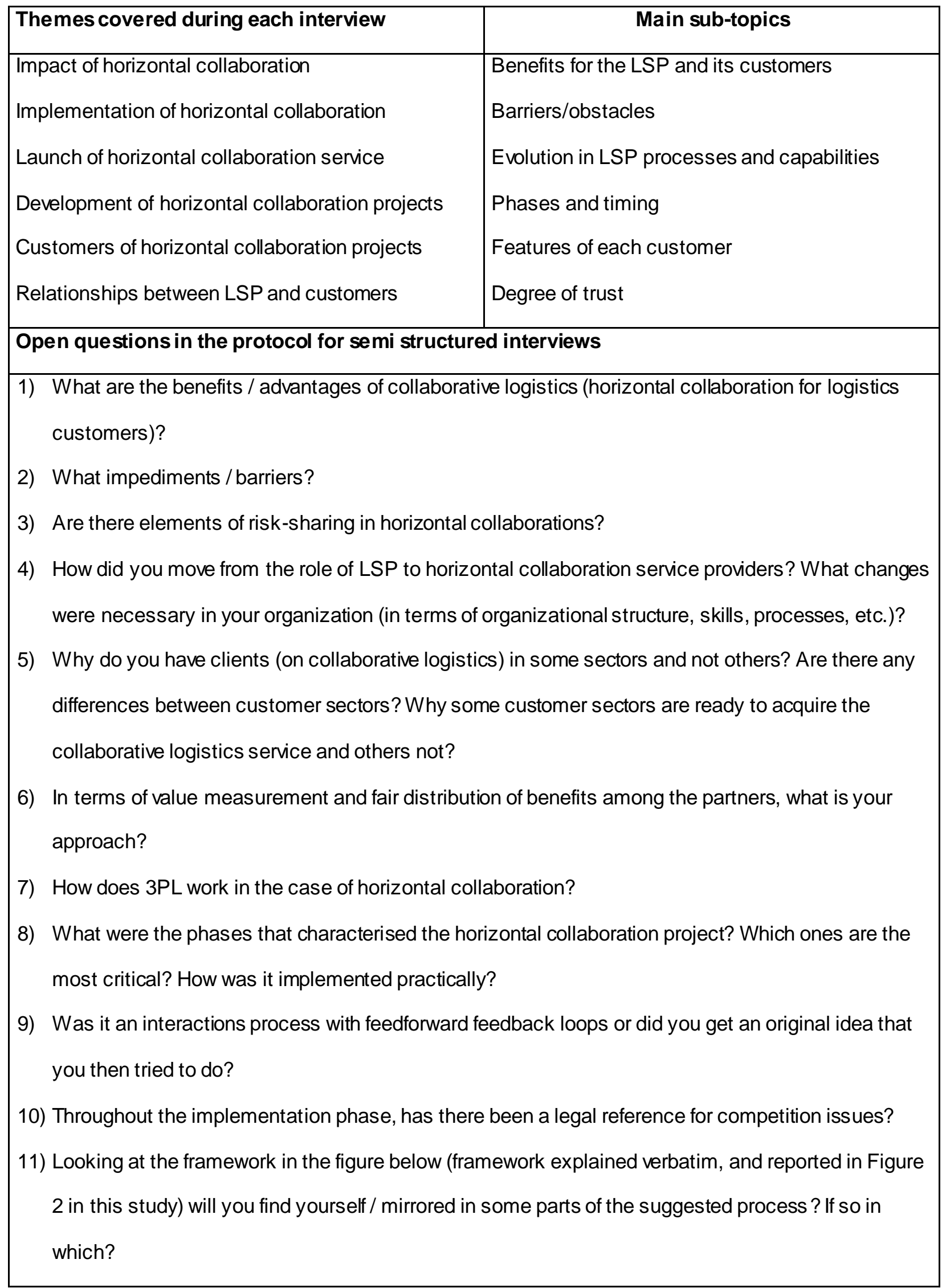

